\title{
The effects of an alien stimulus on reminiscence in pursuit rotor performance
}

C. G. COSTELLO

UNIVERSITY OF CALGARY

Rachman (1962) found that an alien stimulus introduced towards the end of a $5 \mathrm{~min}$ period of practice on a pursuit rotor reduced the reminiscence effect. He interpreted his findings in terms of the disinhibiting effect of the alien stimulus. In the present study, it was found that an alien stimulus alone did not have a significant effect on reminiscence but a significant effect was produced by an alien stimulus supposedly indicating poor performance. The latter finding was in line with prediction from a frustration theory of reminiscence.

Rachman (1962) found that the introduction of an alien stimulus towards the end of a $5 \mathrm{~min}$ period of practice on a pursuit rotor reduced the reminiscence effect after a $10 \mathrm{~min}$ rest period. Adopting the theory that accounts for reminiscence in terms of the dissipation during rest of the reactive inhibition accumulated during performance (Eysenck, 1956; Kimble, 1950), Rachman interpreted his findings in terms of the disinhibiting effects of the alien stimulus. His use of the concept of disinhibition was similar to that of Pavlov (1927).

Interpretation of the findings concerning reminiscence in terms of disinhibition resulted in the further prediction that immediately after presentation of the alien stimulus there would be an augmentation of performance. This prediction was not confirmed.

An alternative explanation for the reminiscence effect in terms of recovery from the frustrating effects of massed practice has been suggested by Costello \& DiScipio (1967). This frustration theory might account for Rachman's findings in terms of the further frustration produced by the noxious alien stimulus. The loudness of the buzzer is not reported by Rachman, but it was not expected by the Ss so that it is probably safe to assume that it was an unpleasant stimulus. Because it was presented only once, no adaptation to the buzzer could occur. Also, when Ss started the post-rest practice they would probably expect the buzzer to sound again. Thus, the normal increased state of relaxation that, according to the frustration theory, a rest period produces would be lessened, and the reminiscence effect would be reduced.

The study reported here was an attempt to test the frustration interpretation by increasing the frustrating nature of the alien stimulus. The members of one of the experimental groups were told that a buzzer would sound only if their performance were poor. It was predicted that by increasing the frustrating nature of the buzzer the reduction in remi- niscence would be greater than that produced by presenting a buzzer with no signal value.

Method

The Ss were 60 male volunteers from an introductory psychology class, randomly assigned to two experimental groups and one control group.

All of the Ss, first of all, had 5 min massed practice on a pursuit rotor identical to that used by Eysenck (1964). This was followed by a $5 \mathrm{~min}$ rest period and a further $5 \mathrm{~min}$ massed practice. No other manipulations or instructions were involved in the case of the control group.

Both of the experimental groups heard a buzzer of $60 \mathrm{~dB}$ for $2 \mathrm{sec}$ after $4 \mathrm{~min} 35 \mathrm{sec}$ of pre-rest practice had elapsed. The members of one of the experimental groups were told prior to their pre-rest performance that the apparatus would automatically sound a buzzer if their performance fell far below average. The spurious criterion of poor performance was purposely left vague. These two experimental groups will be referred to as the "buzzer" group and the "signal-buzzer"' group.

The reminiscence score for each $S$ was the total time on target for the first $10 \mathrm{sec}$ post-rest trial minus the total time on target during the last $10 \mathrm{sec}$ pre-rest trial.

\section{Results and Discussion}

The mean reminiscence scores for the three groups were: control =0.72; "buzzer" $=0.83$; "signal-buzzer" $=0.40$. Analysis of varlance indicated that the between groups effect was statistically significant ( $F=5.06$, $d f=2 / 57, p<.01$ ).

Duncan's multiple range test (Duncan, 1955) indicated that the "signal-buzzer" group had a significantly smaller reminiscence effect than the other two groups $(p<.01)$. The reminiscence effect of the control group and "buzzer" group did not differ significantly.

The results for the control group and the "buzzer" group are not in line with those reported by Rachman (1962). It is possible that the lack of significant effect on reminiscence of the buzzer in the present experiment was due to its low intensity. Unfortunately, since Rachman has not reported the intensity of the buzzer in his experiment, no clear comparisons can be made.

The significant reduction in the reminiscence effect produced by presentation of a buzzer supposedly signalling poor performance is in line with the prediction from the frustration theory proposed. 
References

Costello, C. G., \& DiScipio, W. An experimental tests of a "frustration" theory of reminiscence. Psychon. Sci., 1967, 8,

Duncan, D. B. Multiple range and multiple F tests. Biometrics, 1955, 11, 1-42.

Eysenck, H.J. Experiments in motivation. Oxford: Pergamon Press, 1964.

Eysenck, H. J. Reminiscence, drive and personality theory. $J$. abnorm. soc. Psychol., 1956, 53, 328-333.

Kimble, G. A. Evidence for the role of motivation in determining the amount of reminiscence in pursuit rotor learning. J. exp. Psychol, 1950, 40, 248-253.

Pavlov, I. P. Conditioned reflexes. London: Oxford University Press, 1927.

Rachman, S. Disinhibition and the reminiscence effect in a motor learning task. Brit. J. Psychol., 1962, 53, 149-157. 